\title{
Forecasting recruitment and stock biomass of Northeast Arctic cod using neural networks*
}

\author{
GEIR HUSE ${ }^{1}$ and GEIR OTTERSEN ${ }^{1,2}$ \\ ${ }^{1}$ Institute of Marine Research, PO box 1870 Nordnes, N-5817 Bergen, Norway. E-mail: geir.huse@imr.no \\ ${ }^{2}$ Current address: Division of Zoology, Department of Biology, University of Oslo, PO Box 1050, Blindern, \\ N-0316 Oslo. E-mail: geir.ottersen@bio.uio.no
}

\begin{abstract}
SUMMARY: We apply an artificial neural network (ANN) to predict recruitment and biomass development of Northeast Arctic cod. The ANN is trained using a genetic algorithm with input time series such as spawning stock biomass of cod, herring and capelin biomass, and temperature. Forecasts were made by training the ANN on parts of the time series (training set), and then using a trained ANN to predict cod recruitment or biomass in years outside of the training set. In general the predictions corresponded well to observations. The correlation $\left(\mathrm{r}^{2}\right)$ between observed and predicted stock recruitment at age 3 was 0.74 , based on a model with temperature, spawning stock biomass, and capelin biomass. The correlation between observed and predicted stock biomass was $0.89,0.72$ and 0.57 for one, two and three year predictions respectively. The best model for the one year predictions was based on input information on cod biomass, temperature, and cod landings. These results illustrate the strong forecasting ability of ANN models. In the light of our findings we discuss the potential benefit of applying ANN models as a forecasting technology in fisheries assessment.
\end{abstract}

Key words: cod, forecasting, neural networks, genetic algorithm, recruitment, abundance, temperature, growth, population dynamics.

\section{INTRODUCTION}

A prominent problem in fisheries assessment is to provide prognoses of fish stock development. Estimates of stock development rely on current stock abundance and expectations about future recruitment, individual growth and mortality rates, including fishing mortality. While fishing mortality to a certain degree can be regulated through management, it is difficult to predict recruitment, growth and natural mortality. This is especially a problem when changes in the ecosystem occur, which can alter the vital rates substantially within short time

\footnotetext{
*Received December 6, 2000. Accepted October 10, 2001
}

intervals (Hamre, 1994). One way of getting around this problem is to apply models such as the artificial neural network (ANN, Rummelhart et al., 1986), which is a general computational method, built on principles from neurology. The approach can be used to find patterns in complex data, and has been applied successfully in fisheries science for predicting yields of the Japanese sardine population (Komatsu et al., 1994; Aoki and Komatsu, 1997), yields of African lake fisheries (Laë et al., 1999), capelin biomass (Huse and Gjøsæter, 1999), and recruitment of Pacific herring (Chen and Ware, 1999). Under this approach, relevant input data are associated with the target variable, for example fish biomass in the subsequent year. Through a training 
process, the ANN "learns" how growth and mortality of the target stock tend to be affected by for example the combination of abundance of predators and prey. This "knowledge" is compiled in the weights of the ANN, and given the current state of the time series variables, it can be used to predict stock developments, which may be applied when establishing harvest quotas.

Here we use ANNs to forecast stock dynamics of Northeast Arctic (NA) cod (Gadus morhua) in the Barents Sea (Fig. 1). This arcto-boreal shelf sea can be described as a region of high productivity, but of low biological diversity, i.e. it is rich in fish production, and the fish belong to a few species. Such an ecosystem is attractive to fisheries, but has low stability and may be seriously affected by overexploitation of one or more of the key species in the system (Jakobsson, 1992). In addition to NA cod, which is the main piscivorous stock, the dominating fish species are capelin (Mallotus villosus) and adolescent herring (Clupea harengus). Pronounced inter-annual variation in individual growth is seen in the NA cod stock (Brander, 2000), and this variability is mainly attributed to variation in food abundance (Mehl and Sunnanå, 1991; Yaragina and Marshall, 2000) and temperature (Nakken, 1994; Brander, 2000). Recruitment is also highly variable with a 20-fold range of abundance at age 3 (Nakken, 1994), and a combination of temperature, wind stress, and spawning stock characteristics can explain much of this variability (Ottersen and Sundby, 1995; Marshall et al., 2000). The objective of the current paper is to develop ANN models that can predict recruitment and biomass of NA cod.

\section{INPUT DATA}

Time series of data thought to represent the state of the NA cod stock or processes relevant for its population dynamics were used as input information in the ANN (Table 1). Cod biomass, spawning stock biomass (SSB), and number of recruits (ICES, 2001) are estimated using Virtual Population Analysis (Pope, 1972). Biomass of 1-3 year old herring in the Barents Sea is estimated using acoustics (Gjøsæter and Bogstad, 1998). Data on cod landings are taken from ICES (2001). Capelin biomass is estimated using acoustics during scientific surveys in September-October, and the capelin data are taken from Toresen (2000). Total liver energy (TLE) data for cod were provided by Tara Marshall (see Marshall et al. 2000). The temperature data applied were annual mean temperature of monthly measurements from the Kola meridian transect $\left(33^{\circ} 30^{\prime} \mathrm{E}, 70^{\circ} 30^{\prime} \mathrm{N}\right)$ intersecting the Murman Current in the south central Barents Sea. Here values vertically averaged from 0 $200 \mathrm{~m}$ depth are used. The historical data were taken from Bochkov (1982) and Tereshchenko (1996), while the most recent values were provided by

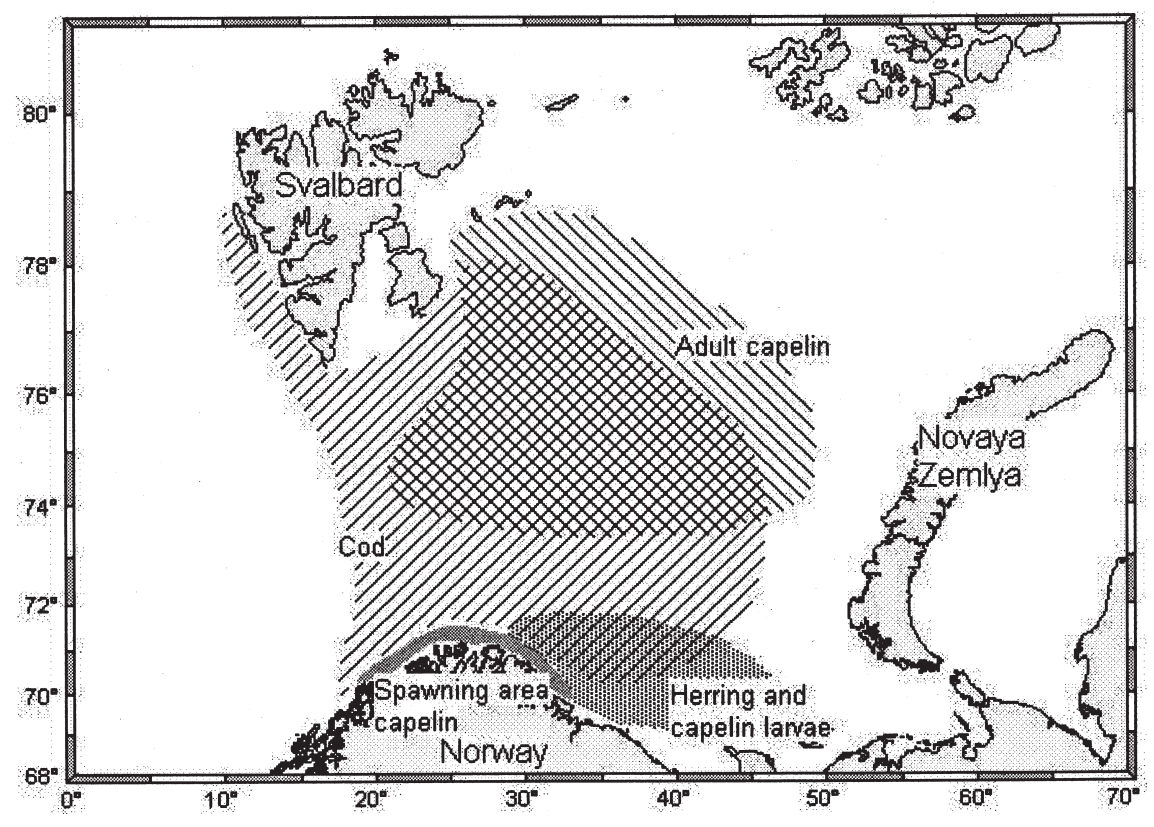

FIG. 1. - The Barents Sea with the main features of the distributions of cod, capelin and herring. Cod prefers feeding on capelin, but turns to herring in years with low capelin abundance. Modified from Huse and Gjøsæter (1999). 
TABLE 1. - Input data to the ANN model. The number of cod recruits at age $3(\mathrm{CR})$ is in billions. The biomass data including cod biomass (CB), spawning stock biomass (CS), landings (CF), capelin biomass (LB), and herring biomass (HB), are in million tonnes. TLE is total cod liver energy in trillion kJ. Average temperature (TA) and the temperature for September (TS) is in ${ }^{\circ} \mathrm{C}$. N refers to the North Atlantic Oscillation. Labels at the bottom of the top row indicate acronyms used in the paper. Herring biomass data are lagged by 2 years in the model, and the biomasses of the years 1972 and 1973 were assumed to be 0 and are not listed in the table (Gjøsæter and Bogstad, 1998).

\begin{tabular}{|c|c|c|c|c|c|c|c|c|c|c|}
\hline Year & $\mathrm{CR}$ & $\mathrm{CB}$ & CS & $\mathrm{CF}$ & TLE & LB & $\mathrm{HB}$ & TA & $\mathrm{TS}$ & $\mathrm{N}$ \\
\hline 1974 & 0.52 & 2.24 & 0.16 & 1.102 & 0.95 & 4.80 & 0.00 & 4.0 & 5.10 & 1.23 \\
\hline 1975 & 0.62 & 2.04 & 0.14 & 0.829 & 1.23 & 7.30 & 0.00 & 4.4 & 5.30 & 1.63 \\
\hline 1976 & 0.61 & 1.93 & 0.17 & 0.867 & 1.31 & 5.80 & 0.00 & 4.1 & 5.40 & 1.37 \\
\hline 1977 & 0.35 & 1.95 & 0.34 & 0.905 & 1.25 & 4.20 & 0.00 & 3.6 & 4.50 & -2.14 \\
\hline 1978 & 0.64 & 1.58 & 0.24 & 0.699 & 1.10 & 4.50 & 0.00 & 3.0 & 3.80 & 0.17 \\
\hline 1979 & 0.20 & 1.11 & 0.17 & 0.441 & 0.71 & 4.10 & 0.00 & 2.9 & 4.00 & -2.25 \\
\hline 1980 & 0.14 & 0.86 & 0.11 & 0.380 & 0.43 & 5.50 & 0.00 & 3.6 & 4.70 & 0.56 \\
\hline 1981 & 0.15 & 0.98 & 0.17 & 0.399 & 0.42 & 3.00 & 0.00 & 3.2 & 4.00 & 2.05 \\
\hline 1982 & 0.15 & 0.75 & 0.33 & 0.364 & 0.44 & 2.50 & 0.00 & 3.7 & 5.00 & 0.8 \\
\hline 1983 & 0.17 & 0.74 & 0.33 & 0.290 & 1.47 & 2.60 & 0.00 & 4.6 & 5.90 & 3.42 \\
\hline 1984 & 0.40 & 0.82 & 0.25 & 0.278 & 0.32 & 2.40 & 0.31 & 4.1 & 5.10 & 1.6 \\
\hline 1985 & 0.52 & 0.96 & 0.19 & 0.308 & 0.34 & 0.70 & 0.87 & 3.7 & 4.60 & -0.63 \\
\hline 1986 & 1.04 & 1.29 & 0.17 & 0.430 & 0.22 & 0.08 & 0.26 & 3.7 & 4.60 & 0.5 \\
\hline 1987 & 0.29 & 1.12 & 0.12 & 0.523 & 0.17 & 0.02 & 0.00 & 3.4 & 4.20 & -0.75 \\
\hline 1988 & 0.20 & 0.91 & 0.20 & 0.435 & 0.12 & 0.40 & 0.00 & 3.8 & 4.60 & 0.72 \\
\hline 1989 & 0.17 & 0.89 & 0.19 & 0.332 & 0.15 & 0.30 & 0.02 & 4.5 & 5.80 & 5.08 \\
\hline 1990 & 0.24 & 0.96 & 0.34 & 0.212 & 0.17 & 3.20 & 0.05 & 4.6 & 5.50 & 3.96 \\
\hline 1991 & 0.41 & 1.56 & 0.68 & 0.319 & 0.47 & 5.60 & 0.49 & 4.5 & 5.40 & 1.03 \\
\hline 1992 & 0.72 & 1.91 & 0.87 & 0.513 & 0.86 & 3.90 & 1.67 & 4.6 & 5.40 & 3.28 \\
\hline 1993 & 0.89 & 2.35 & 0.73 & 0.582 & 0.94 & 0.80 & 1.52 & 4.1 & 4.90 & 2.67 \\
\hline 1994 & 0.81 & 2.14 & 0.60 & 0.771 & 0.73 & 0.10 & 2.86 & 3.8 & 4.90 & 3.03 \\
\hline 1995 & 0.66 & 1.82 & 0.50 & 0.740 & 0.71 & 0.15 & 0.63 & 4.3 & 5.55 & 3.96 \\
\hline 1996 & 0.43 & 1.69 & 0.57 & 0.732 & 0.42 & 0.26 & 0.10 & 3.8 & 4.85 & -3.78 \\
\hline 1997 & 0.71 & 1.53 & 0.57 & 0.762 & 0.50 & 0.49 & & 3.6 & 4.60 & -0.2 \\
\hline 1998 & 0.87 & 1.23 & 0.39 & 0.593 & & 1.25 & & 3.6 & 4.60 & 0.72 \\
\hline 1999 & 0.56 & 1.08 & 0.26 & 0.485 & & 2.12 & & 4.2 & 5.00 & 1.89 \\
\hline
\end{tabular}

PINRO, Murmansk. We used annual means of monthly values for the biomass predictions, and values for September in the recruitment predictions, based on the results of some test runs. The North Atlantic Oscillation (NAO), an alternation in the sea level air pressure difference between the Azores high and Icelandic low, is an important source of seasonal to decadal-scale climatic variability in the North Atlantic sector (Hurrell, 1995). NAO winter (December-March) indices, slightly modified from the index of Hurrell (1995), were obtained from the web page of Jim Hurrell of NCAR's Climate and Global Dynamics Division (http://www.cgd.ucar.edu/ jhurrell/nao.html).

\section{THE MODEL}

Mathematically, the ANN is a sophisticated multiple regression model. ANNs find patterns by differential weighting of input data, analogous to the way our brain is thought to "calculate" responses from stimuli. For an introduction to ANNs see Anderson (1995), and for ecological and fisheries applications see Saila (1996), Lek and Guegan (1999) and Huse and Gjøsæter (1999). The weights of ANNs can be trained using a variety of techniques, and here the weights are adapted using the genetic algorithm (GA, Holland, 1975). A general introduction to GAs is provided by Mitchell (1996), and van Rooij et al. (1996) give a presentation of how to use the GA in training ANNs. The GA applies the Darwinian principle of evolution by natural selection to search for increasingly better solutions to complex problems. It works by having a population of solutions in which each solution here is an ANN with a unique set of weights (Fig. 2). These solutions compete like individuals in a natural population, and the best solutions in each generation are continuously reproduced and improved using random changes (mutations) in the weights. After a sufficient number of generations, the ANNs are well adapted to the training set and can be used in forecasting. The model used here is a modified version of the model presented by Huse and Gjøsæter (1999).

\section{Network architecture}

A fully connected feed forward ANN (Rummelhart et al., 1986) was used with an input, one hidden and an output layer (Fig. 2). Each layer consists of 


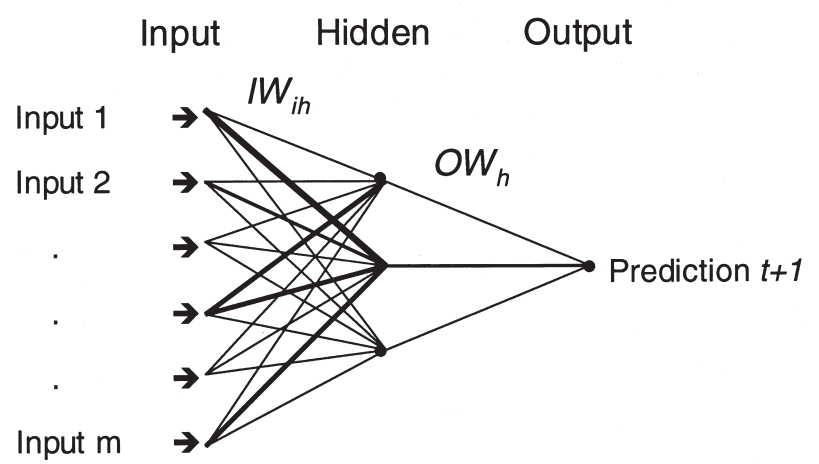

FIG. 2. - The ANN used. The input data (Table 1) are weighted by the connection strength between the input and hidden layers $\left(I W_{i n}\right)$, added together including the biases at each hidden node, and transformed. The data are then multiplied by the weights of connection between the hidden and output nodes $\left(O W_{h}\right)$ and these sums are added together and transformed at the output node to produce forecasts. Differences in thickness of lines illustrate the variation in connection strength among different nodes.

nodes, which are either input data, connection points where summations and transformations of data occur, or output data. An example of how predictions are calculated from a trained network using the equations below is provided in the Appendix. The calculations proceed sequentially from the input, via the hidden layer to the output layer, and this process is described in Eqs. 1-4. The input data (Table 1) are standardised so that the maximum value of each time series is 1 , and multiplied by the weights between the input and hidden layers (Fig. 2):

$$
N_{h}=\sum_{i=1}^{m} I W_{i h} \cdot I_{i}
$$

where $I_{i}$ is the input data of input node $i$ (Table 1), $I W_{i h}$ is the connection weight between input data $i$ and hidden node $h, N_{h}$ is the sum of the weighted input data of hidden node $h$, and $m$ is the number of input nodes. At the hidden node, values are transformed using the standard sigmoid transformation:

$$
T N_{h}=\frac{1}{\left(1+e^{-\left(N_{h}+B_{h}\right)}\right)}
$$

where $T N_{h}$ is the transformed value and $B_{h}$ is the bias (van Rooij et al., 1996) of hidden node $h$. The bias $B_{h}$ is similar to an intercept value in a regression model. Next the output value $P$ is calculated by adding together the sums of the transformed hidden node values multiplied by the output weights $\left(O W_{h}\right)$ :

$$
P=\sum_{h=1}^{2} O W_{h} \cdot T N_{h}
$$

The output is then transformed and scaled $(S$, Table 1) from values between 0 and 1 to the observed recruitment or biomass level. This yields the forecast output of the model $T P_{t}$ :

$$
T P_{t}=\frac{S}{\left(1+e^{-P}\right)}
$$

where $t$ refers to the year for which the forecast is made. The weights and biases are initiated randomly between -1 and 1 , but as a result of the training process, they may move out of this range.

\section{The GA}

A population of 2000 weight sets is initiated randomly at generation number 1 . This population is then evolved using the GA, to seek the best combination of weights for minimising the discrepancy between predictions and observations (Eq. 5). The sum of the squared discrepancies between the annually predicted $\left(T P_{t}\right)$ and observed $\left(O_{t}\right)$ values from the initial year $(I Y)$ to the final year $(F Y)$ of the training set is here applied as a measure of model performance during training:

$$
E=\sum_{t=I Y}^{F Y}\left(T P_{t}-O_{t}\right)^{2}
$$

For the recruitment and biomass forecasts, $O_{t}$ will be the $\mathrm{CR}$ and $\mathrm{CB}$ values respectively (Table 1 ). The error value $(E)$ is used in the GA to rank the solutions, and the solutions with the lowest $E$ are selected to be parents for the next generation. The error term is independent of the number of input variables. The parameter values used in the GA are given in Table 2. New weight sets are based on the weights of parents, which are the 400 best solutions in each generation. It is common to use recombination in GAs, but when used for training ANNs it can be counter productive since recombinations tend to break down the ANN structure. Thus we only introduced weight variability through mutations. Mutations are performed randomly with a probability of occurring of $10 \%$ per weight or bias per generation (Table 2). When a mutation occurs, a value chosen randomly from the initiation range $[-1,1]$ is added to the weight value. The new generation is then put through the test described above, and once again the best ones are selected and mutated. By carrying out this procedure over many generations, increasingly better solutions to the problem will emerge. To avoid over-training (Geman et al., 1992), the number of hidden nodes was kept at two, which gave the best performance for most models, and the number of generations was kept low (Table 2). 
TABLE 2. - Parameter values used in the model.

\begin{tabular}{|c|c|}
\hline Parameter & Value \\
\hline $\begin{array}{l}\text { Mutation probability in } \\
\quad \text { weights and biases } \\
\text { Mutation effect in weights } \\
\quad \text { and biases } \\
\text { Number of offspring per parent } \\
\text { Parent selection } \\
\text { Partner selection } \\
\text { Generations per run } \\
\text { Population size } \\
\text { Number of replicate runs } \\
\text { Output scaling, } S\end{array}$ & $\begin{array}{l}0.1 \\
\text { randomly between }-1 \text { and } 1 \\
5 \\
400 \text { best individuals } \\
\text { among } 80 \% \text { of best individuals } \\
25 \\
2000 \\
10 \\
3 \text { in recruitment runs, } 6 \text { in } \\
\text { biomass runs }\end{array}$ \\
\hline
\end{tabular}

\section{Evaluation procedure}

In each simulation, parts of the time series are used as a training set, which contains the data used to adapt the ANN. Two different sorts of simulations were performed based on training over the entire time series except the prediction year (full training set), and training only over the time series prior to the prediction year (reduced training set) respectively. In the latter case, the training set increases from the start to the end of the time series, and for predictions made at the end of the time series, the reduced training set is equal to the full training set. Following training, the value of the prediction year, not included in the training set, was predicted. Different input data were tested for their ability to contribute in predicting the observed cod dynamics, and several combinations of input data were left out of the presentation due to their poor performance. When referring to different "models" here we generally mean ANN simulations relying on different input data. Recruitment forecasts of 3 year old cod were made at the year of birth. Biomass forecasts were made one, two and three years ahead. A weight analysis was performed to shed light on the importance of the different input data. In general, weight values indicate importance to the behaviour of ANN models, with larger weights being more important than smaller ones (Aoki and Komatsu, 1997).

Since the results of a computer run to some extent depend on the initial weights and the mutations, which are dependent on random numbers, ten replicate trials were performed for all computer simulations. The average values of these replicate runs are presented here. The Pearson correlation coefficient $\left(r^{2}\right)$ between observations and predictions was used as a measure of model fit to observations.

\section{RESULTS}

\section{Recruitment forecast}

The results of the recruitment forecasts show that the ANN model using temperature alone provides a reasonably high predictive ability (Table 3 ). The NAO time series on the other hand provided a lower forecasting ability, and the model based on temperature and NAO performed worse than the model relying solely on temperature. In addition to these physical factors, we tested several biological variables. Three proxies relating to the state of the spawning stock were tested including spawning stock biomass, total liver energy (TLE) of the cod population, and the biomass of capelin, which is the main prey of cod. Models based on these data performed similarly when used together with temperature (Table 3). The overall best model relied on capelin biomass, SSB and temperature as input data (Fig. 3), and this model provided forecasts with $\mathrm{r}^{2}=0.74$. In general, this model has problems in recreating the highest peaks in recruitment such as in 1983 (Fig. 3). The simulations with reduced training sets performed worse than the simulations with full training sets, especially for the first part of the time series. Towards the end of the time series when the reduced set is rather large, the predictions are quite similar (Fig. 3). The weight analysis of the best model ranked cod spawning stock biomass as the

TABLE 3. - Pearson correlations $\left(\mathrm{r}^{2}\right)$ between predicted and observed cod recruitment at age 3 based on ANN model simulations with different input data. The results are averages of 10 replicate runs. See Table 1 for acronym definitions. Forecasts are made for 3 -year-old cod over the time series 1979-1999, and $t$ is defined as the year of birth. The models are sorted by their forecasting ability in ascending order. The numbers in brackets give the total number of weights and biases used in each model.

\begin{tabular}{|c|c|c|c|c|c|c|c|c|}
\hline Forecast & $\begin{array}{l}\mathrm{CS}_{\mathrm{t}} \\
(6)\end{array}$ & $\begin{array}{l}\mathrm{N}_{\mathrm{t}} \\
(6)\end{array}$ & $\begin{array}{c}\mathrm{TS}_{\mathrm{t}}, \mathrm{N}_{\mathrm{t}} \\
(8)\end{array}$ & $\begin{array}{l}\mathrm{TS}_{\mathrm{t}} \\
(6)\end{array}$ & $\begin{array}{l}\text { Input data } \\
\mathrm{TS}_{\mathrm{t}} \mathrm{CS}_{\mathrm{t}} \\
\text { (8) }\end{array}$ & $\begin{array}{c}\mathrm{TS}_{\mathrm{t}}, \mathrm{TLE}_{\mathrm{t}-1} \\
(8)\end{array}$ & $\begin{array}{c}\mathrm{TS}_{\mathrm{t}}, \mathrm{LB}_{\mathrm{t}-1} \\
(8)\end{array}$ & $\begin{array}{c}\mathrm{TS}_{\mathrm{t}}, \mathrm{CS}_{\mathrm{t}}, \mathrm{LB}_{\mathrm{t}-1} \\
(10)\end{array}$ \\
\hline $\mathrm{R}_{\mathrm{t}+3}$ & 0.27 & 0.42 & 0.45 & 0.54 & 0.59 & 0.59 & 0.60 & 0.74 \\
\hline
\end{tabular}




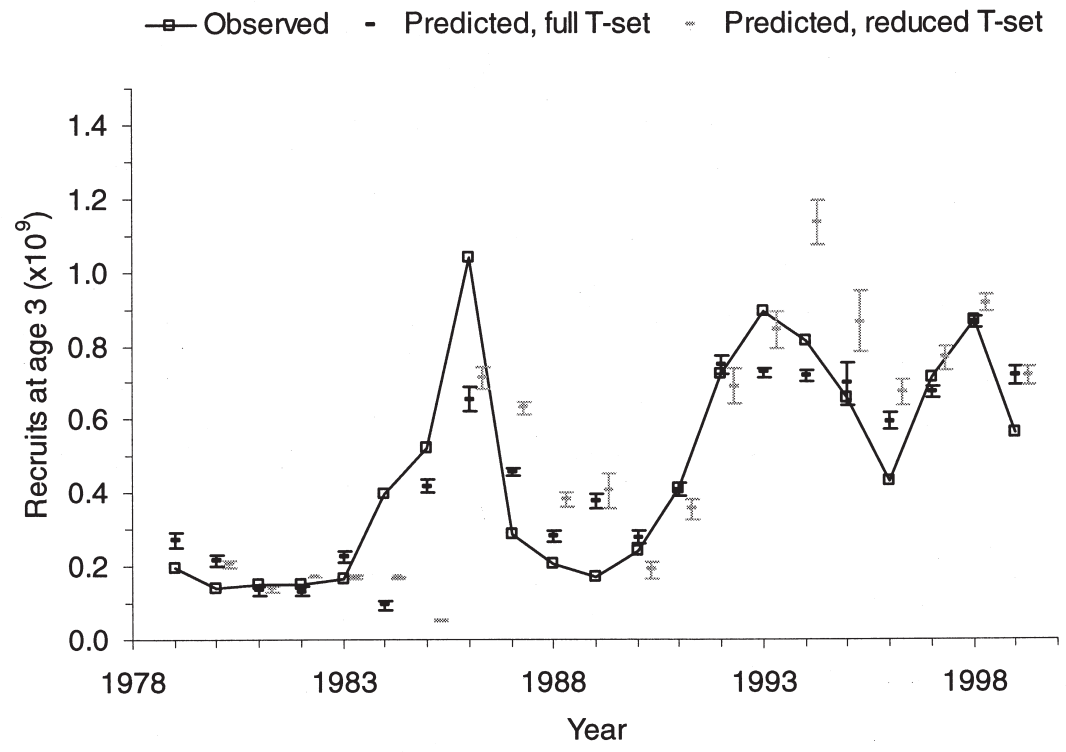

FIG. 3. - Observed and predicted number of 3-year-old cod based on information about temperature $\left(\mathrm{TS}_{\mathrm{t}}\right)$, cod spawning biomass $\left(\mathrm{CS}_{\mathrm{t}}\right)$, and capelin biomass $\left(\mathrm{LB}_{\mathrm{t}}\right)$. Average values and confidence limits of replicate runs are shown. For the predictions based on the full training set (Tset) the correlation was $r^{2}=0.74$, while with the reduced training set it was $r^{2}=0.60$.

TABLE 4. - Pearson correlations $\left(\mathrm{r}^{2}\right)$ between predicted and observed cod biomasses based on ANN model simulations with different input data. The subscripts on the variable names give the time lag of the input data and forecasts. Values are average of 10 replicate runs. See Table 1 for acronym definition. The models are sorted by their forecasting ability for $t+1$ in ascending order. The numbers in brackets give the total number of weights and biases used in each model.

\begin{tabular}{|c|c|c|c|c|c|c|c|c|}
\hline Forecast & $\begin{array}{c}\mathrm{CB}_{t}, \mathrm{LB}_{\mathrm{t}} \\
(8)\end{array}$ & $\begin{array}{l}\mathrm{CB}_{\mathrm{t}} \\
(6)\end{array}$ & $\begin{array}{c}\mathrm{CB}_{\mathrm{t}}, \mathrm{TA}_{\mathrm{t}} \\
\text { (8) }\end{array}$ & $\begin{array}{c}\mathrm{CB}_{\mathrm{t}}, \mathrm{TA}_{(10)}, \mathrm{N}_{\mathrm{t}} \\
\end{array}$ & $\begin{array}{c}\text { Input data } \\
\mathrm{CB}_{\mathrm{t}}, \mathrm{TA}_{\mathrm{t}}, \mathrm{HB}_{\mathrm{t}-2}, \mathrm{LB}_{\mathrm{t}} \\
\text { (12) }\end{array}$ & $\mathrm{CB}_{\mathrm{t}}, \underset{(10)}{\mathrm{TA}_{\mathrm{t}}, \mathrm{HB}_{\mathrm{t}-2}}$ & $\begin{array}{c}\mathrm{CB}_{\mathrm{t}}, \mathrm{TA}_{\mathrm{t}}, \mathrm{LB}_{\mathrm{t}} \\
\text { (10) }\end{array}$ & $\mathrm{CB}_{\mathrm{t}}, \underset{(10)}{\mathrm{TA}_{\mathrm{t}}, \mathrm{CF}_{\mathrm{t}}}$ \\
\hline $\mathrm{CB}_{\mathrm{t+1}}$ & 0.71 & 0.72 & 0.83 & 0.83 & 0.83 & 0.85 & 0.87 & 0.89 \\
\hline $\mathrm{CB}_{\mathrm{t+1}}^{\mathrm{t+1}}$ & 0.36 & 0.39 & 0.72 & 0.67 & 0.65 & 0.70 & 0.69 & 0.72 \\
\hline $\mathrm{CB}_{\mathrm{t}+3}^{\mathrm{t}+2}$ & 0.02 & 0.05 & 0.47 & 0.44 & 0.57 & 0.45 & 0.50 & 0.42 \\
\hline
\end{tabular}

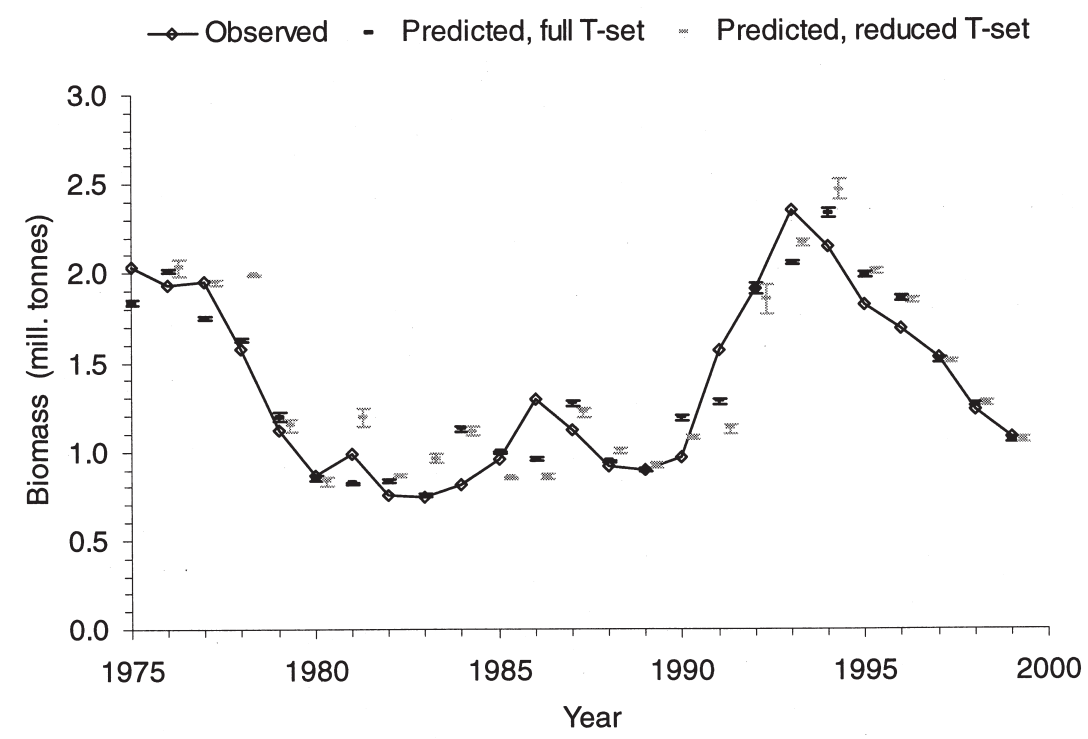

FIG. 4. - Observed and predicted biomass of NA cod one year ahead based on input information about cod biomass $\left(\mathrm{CB}_{\mathrm{t}}\right)$, cod landings $\left(\mathrm{CF}_{\mathrm{t}}\right)$ and temperature $\left(\mathrm{T}_{\mathrm{t}}\right)$. Average values and confidence limits of replicate runs are shown. For the predictions based on the full training set (Tset) the correlation was $r^{2}=0.89$, while with the reduced time series it was $r^{2}=0.84$. 


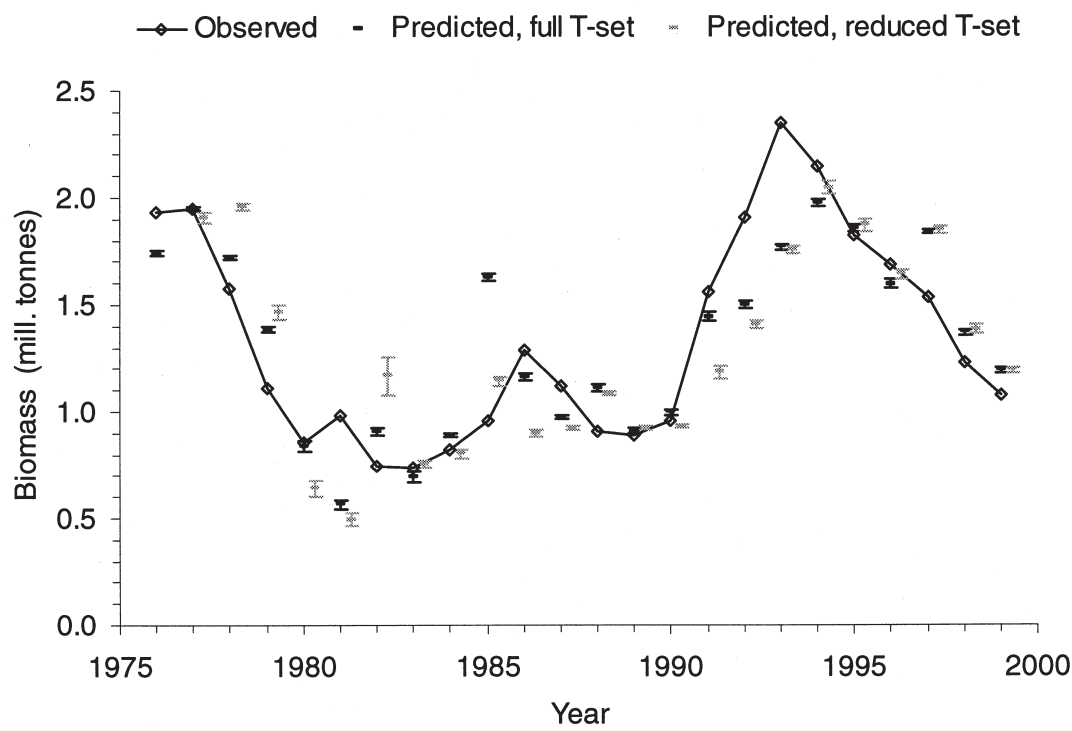

FIG. 5. - Observed and predicted biomass of NA cod two years ahead based on input information about cod biomass $\left(\mathrm{CB}_{\mathrm{t}}\right)$ and temperature $\left(\mathrm{T}_{\mathrm{t}}\right)$. Average values and confidence limits of replicate runs are shown. For the predictions based on the full training set (T-set) the correlation was $\mathrm{r}^{2}=0.72$, with the reduced training set it was $\mathrm{r}^{2}=0.65$.

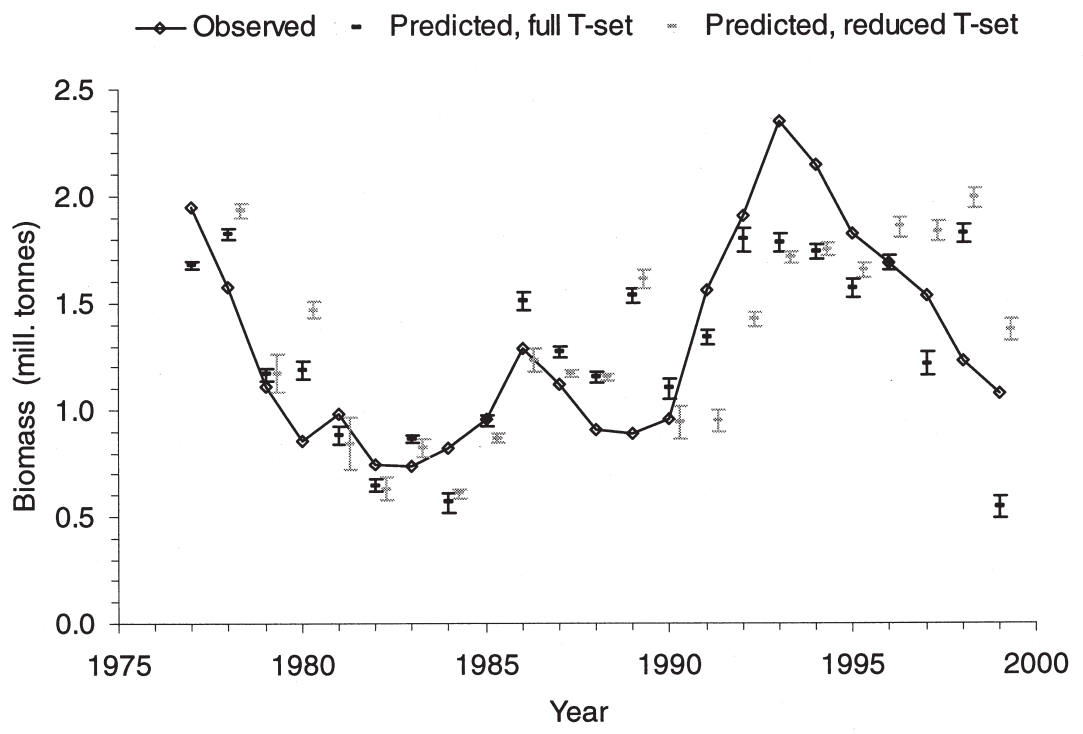

FIG. 6. - Observed and predicted biomass of NA cod three years ahead based on input information about cod biomass (CB $)$, capelin biomass $\left(\mathrm{LB}_{\mathrm{t}}\right)$, herring biomass $\left(\mathrm{HB}_{\mathrm{t}-2}\right)$, and temperature $\left(\mathrm{T}_{\mathrm{t}}\right)$. Average values and confidence limits of replicate runs are shown. For the predictions based on the full training set (T-set) the correlation was $\mathrm{r}^{2}=0.57$, with the reduced training set it was $\mathrm{r}^{2}=0.41$.

most important contributor to the output followed by capelin biomass and temperature.

\section{Forecast of total stock biomass}

The different input data varied greatly in their ability to predict adult cod dynamics (Table 4). The models based solely on input information about cod biomass performed reasonably well in predicting biomass development one year ahead, but were much worse for the longer term predictions (Table 4). The best model for one year predictions was based on cod biomass, cod landings, and temperature as input variables (Fig. 4). This model produced one year forecasts with $r^{2}=0.89$. The average difference between the predicted and observed biomass estimate for this model was 0.12 mill. tonnes, and the maximum discrepancy was 0.33 mill. tonnes. As expected, the forecasting ability of the models was reduced for the two (Fig. 5) and three (Fig. 6) year forecasts. For two-year predictions, a model based only on temperature and cod biomass performed as well as the one 
with landings included (Table 4). A different model still, based on cod, herring and capelin biomass, and temperature performed best for the three year predictions. In general, models based on full training sets performed better than the models based on reduced training sets, and the discrepancy increased with increasing time span of predictions (Figs. 4-6). When relying on the reduced training set, models typically produced rather poor estimates for the first part of the time series, while the performance improved towards the end of the time series along with the increase in the training set. The weight analysis showed that cod biomass and temperature have average weights of the same magnitude, while the landings data had smaller average weight.

\section{DISCUSSION}

\section{Recruitment}

The number of studies in which attempts have been made to explain recruitment variability in marine fish populations by means of fluctuations in population parameters and the environment is extensive. Since the stock-recruitment relation for most stocks is weak, much attention has been given to environment-recruitment correlations and many studies have been able to explain a reasonably large part of the recruitment variability during the period studied. However, a recent review is rather discouraging (Myers, 1998). Published environment-recruitment correlations were tested for an extended or different period and the proportion that was verified was low. Nevertheless, there was one generalisation that stood out. Correlations for populations at the limit of a species' geographic range often remained statistically significant when re-examined. This generalisation is further supported by Planque and Frédou (1999). Several other studies have also pointed to the importance of temperature in explaining recruitment in NA cod (Nakken, 1994; Ottersen and Sundby, 1995; Brander, 2000; Sundby, 2000; Dippner and Ottersen, 2001). It is therefore not surprising that we are able to explain much of the recruitment variation observed for NA cod by means of temperature. However, in the current study model fit was improved considerably (from $r^{2}=0.54$ to $r^{2}=0.74$ ) when input data on spawning stock state were added to the temperature-based model. This is supported by Ottersen and Sundby (1995), whose best model relied on abundance of 3 year old cod one year (positive con- tribution) and three years earlier (negative contribution), in addition to temperature and SSB. This autoregressive model explained around $70 \%$ of the total variability in the recruitment time series, similar to our best model. Recent contributions (Marshall et al., 1999; Marshall et al., 2000) have further shown that in NA cod, TLE-recruitment correlations are much stronger than SSB-recruitment correlations. Our results did not show a great difference in model performance among the three indicators of spawning stock state when used with temperature. Overall, the combination of capelin biomass, spawning stock biomass, and temperature provided the best predictive ability. Recruitment in NA cod is therefore best explained as a combination of spawning stock state and environmental factors, as seen in previous studies as well (Ottersen and Sundby, 1995; Marshall et al., 2000). It should be noted, that as opposed to the studies referred to above, and indeed most earlier work, in which the models explain variability during the time period on which they were developed, we present real predictions made three years ahead of the actual recruitment to the stock.

\section{Biomass predictions}

The biomass of cod in any given year is a result of the biomass at the start of the year minus the loss through natural mortality and fisheries, plus the growth and recruitment to the stock during the year. These dynamics are implicit in the biomass data for cod, and as a consequence the ANN adapts to all these processes during the training. The state of the stock is represented by the biomass level at the prediction point, and the processes taking place are represented by proxies such as the temperatures at a fixed position, or the biomass of prey. In addition to being important for recruitment, temperature is known to strongly affect growth of NA cod (Michalsen et al., 1998; Brander, 2000). The first order autocorrelation in cod biomass is high $\left(r^{2}=0.75\right)$, and it is therefore not surprising that the best biomass prediction models had a common reliance on temperature and cod biomass. This was also seen in the weight analysis in which these input data were found to have the greatest weights, and thus contributed the most to the output. An ANN forecasting model for capelin biomass, which has a first order autocorrelation of 0.55 , had about the same performance as the current cod model (Huse and Gjøsæter, 1999). Thus, high autocorrelation in stock biomass is not a prerequisite for good perfor- 
mance of ANNs. Autocorrelation in cod biomass is much weaker for two $\left(r^{2}=0.36\right)$ and three $\left(r^{2}=0.09\right)$ years than for one year. In spite of this, the ANN predictions remained rather strong with correlation coefficients of 0.72 and 0.57 respectively. ANN based models may therefore be useful for medium term forecasting of stock biomass.

The collapses in the Barents Sea capelin stock in the mid eighties and early nineties led to reduced growth and fecundity in cod (Bogstad and Mehl, 1997). Furthermore, increased cannibalism among cod during periods of low capelin abundance has been suggested (Ponomarenko and Ponomarenko, 1975; Sundby et al., 1989), although Bogstad et al. (1994) found little support for this hypothesis. Such events may have changed the relationships between variables in the current model substantially. We tried to implement proxies for cannibalism, but none of these seemed to be important for model performance. An example of how changes in key variables may affect ANN performance has been presented for the Barents Sea capelin (Huse and Gjøsæter, 1999). High abundance of juvenile herring in the Barents Sea has a strong negative impact on capelin recruitment, and is the cause of the recent capelin stock collapses (Hamre, 1994; Gjøsæter and Bogstad, 1998; Huse and Toresen, 2000). An ANN model using a training set from a period without herring in the Barents Sea performed very poorly in predicting the dynamics for a period when herring was present in the Barents Sea. This illustrates the importance of having a representative training set when forecasting stock developments. For NA cod, the biomass predictions seem to be little affected by the inclusion of the years after 1990 in the training set, since the model based on the full and reduced training sets performed similarly for this period (Fig. 4). These results are encouraging with regard to the generality of the model in predicting dynamics of future years, which suggests that the model predictions should not necessarily change too much given the inclusion of new years in the training set. The latter has sometimes been raised as a criticism against the use of ANNs, and the potential effect is illustrated by the capelin case discussed above.

The data used as input in the model are generally not available at the start of the year. Their availability rather depends on the timing of the surveys used to gather them, or the scientific meetings used to estimate them. For example, the capelin biomass is not measured until September, only three months prior to the prediction point of cod biomass at Janu- ary $1\left(\mathrm{CB}_{\mathrm{t}+1}\right)$. Some of the models tested therefore provided less than 12 months predictions, although they are listed as one year predictions.

\section{Fish stock assessment}

Providing prognoses about fish stock development is a prominent part of fisheries assessment. The approach used here can have two main areas of application in fisheries assessment: predicting stock recruitment, and providing prognoses of biomass development given that a traditional fishing pattern is performed on the stock. Since fairly reliable prognoses of recruitment are made three years ahead, forecasts for several year classes can in fact be made. Such information is important for the expectations about future stock development of NA cod. The ANN model also provided quite strong forecasting abilities for cod biomass. Fishing mortality is an integral part of the dynamics of NA cod that is difficult to eliminate from the analysis. The current approach can therefore not be used for studying the effect of different levels of fishing mortality on stock dynamics. Instead, historic fishing mortalities are an integral part of the population dynamics of NA cod, and the ANN is consequently trained to the fishing pattern exerted on the NA cod. This is intrinsic to the ANN model regardless of whether cod landings are used as an input factor or not. The correlation between landings and cod biomass in the following year is very high $\left(r^{2}=0.85\right)$, explaining why the best model relied on cod landings as an input factor. Obviously, this does not imply a causal relationship, suggesting that there is a high cod biomass because the landings are large, but landings are a good proxy for subsequent cod biomass.

An assessment concept could alternatively be built using separate models for each age group, which would be more in line with current stock assessment procedures in which one is often interested in knowing the change in stock structure. Also, different age or size groups generally experience similar patterns in growth and distribution, which may improve the forecasting ability of the model. Another way of applying ANNs in fisheries assessment could be to forecast collapses in stock abundance, for example biomass reductions greater than some target value. We did not attempt this, but for stocks, such as the Barents Sea capelin, where collapses do indeed occur (Gjøsæter, 1998), it can be an interesting analysis to make, that may provide early warning of negative trends. 


\section{Pros and cons}

A potential disadvantage of the ANN approach, as for most statistical models, is that there is no specification of the processes involved. This means that although we can get a predictive ability we do not achieve an understanding of the mechanisms causing the specific relationship between the variables. We are therefore still limited by the available datasets and the "knowledge" compiled in the weights rather than a mechanistic understanding of the phenomenon. In order to provide better understanding there is a need for models that build on evolutionary and ecological principles to provide answers to "what if" questions. However, such models (Fiksen et al., 1995; Giske et al., 1998; Huse and Giske, 1998) are currently not advanced to a state where they can be applied in fisheries management.

The current way of using the ANN has many similarities with standard multiple regression. Nevertheless, ANNs have been shown to perform better than multiple regression under ecological scenarios similar to the current (Brey et al., 1996; Chen and Ware, 1999; Laë et al., 1999). Adding more parameters in multiple regression models can be counter-productive. Although it increases the fit to data, predictive power is generally lost (Hilborn and Walters, 1992). The number of free parameters used in the current ANN models varied between 6 and 12 . Even though the training error (Eq. 5) often was reduced when input variables were added to the training set, the predictive ability of the models was not improved in the same manner. Thus neither for the recruitment or biomass forecasts were the best models those with the greatest number of free variables (Tables 3 and 4).

The advantage of the ANN approach is its ability to predict biomass developments without the need to directly specify parameter values such as growth or mortality rates, which are difficult to establish ahead. Rather these are specified implicitly in the weights of the ANN by relating input data to the resulting dynamics and use these relationships to train the network. By combining several variables the network can predict the dynamics given the current state of the input variables. The ability of the model to react to environmental changes in a broad sense and predict the response of the target feature, be it recruitment or biomass dynamics, is thus the particular strength of ANN models. ANNs are good at sorting out non-linear relations, which are com- mon in fish population dynamics, and could readily be applied as a forecasting technology for recruitment and biomass in fisheries assessment.

\section{ACKNOWLEDGEMENTS}

We thank Jarl Giske, Øyvind Fiksen and two anonymous referees for comments on a former version of this manuscript. Tara Marshall kindly provided the TLE data. GH was supported by the European Commission and GO was supported by the Research Council of Norway. This work was done within the framework of the international GLOBEC program.

\section{REFERENCES}

Anderson, J.A. - 1995. An Introduction to Neural Networks. The MIT Press, Cambridge, MA.

Aoki, I. and T. Komatsu. - 1997. Analysis and prediction of the fluctuation of sardine abundance using a neural network. Oceanol. Acta, 20: 81-88.

Bochkov, Y.A. - 1982. Water temperature in the $0-200 \mathrm{~m}$ layer in the Kola-Meridian in the Barents Sea, 1900-1981. Sb. Nauchn. Trud. PINRO, 46: 113-122.

Bogstad, B., G. Lilly, S. Mehl, O. Palsson and G. Stefansson. 1994. Cannibalism and year-class strength in Atlantic cod (Gadus morhua L.) in Arcto-boreal ecosystems (Barents Sea, Iceland, and eastern Newfoundland). ICES Mar. Sci. Symp., 198: 576-599.

Bogstad, B. and S. Mehl. - 1997. Interactions between Atlantic cod (Gadus morhua) and its prey species in the Barents Sea. In: The role of Forage Fish in Marine Ecosystems, pp. 591-615. Alaska Sea Grant, Anchorage, Alaska.

Brander, K. - 2000. Effects of environmental variability on growth and recruitment in cod (Gadus morhua) using a comparative approach. Oceanol. Acta, 23: 485-496.

Brey, T., T. Jarre-Teichmann and O. Borlich. - 1996. Artificial neural networks versus multiple linear regression: predicting P/B ratios from empirical data. Mar. Ecol. Prog. Ser., 140: 251-256.

Chen, D.G. and D.M. Ware. - 1999. A neural network model for forecasting fish stock recruitment. Can. J. Fish. Aquat. Sci., 56: 2385-2396.

Dippner, J. and G. Ottersen. - 2001. Cod and climate variability in the Barents Sea. Clim. Res., 17: 73-82.

Fiksen, Ø., J. Giske and D. Slagstad. - 1995. A spatially explicit fitness-based model of capelin migrations in the Barents Sea. Fish. Oceanogr., 4: 193-208.

Geman, S., E. Bienenstock and R. Doursat. - 1992. Neural networks and the bias-variance dilemma. Neural Comp., 4: 1-58.

Giske, J., G. Huse and Ø. Fiksen. - 1998. Modelling spatial dynamics of fish. Rev. Fish Biol. Fish., 8: 57-91.

Gjøsæter, H. - 1998. The population biology and exploitation of capelin (Mallotus villosus) in the Barents Sea. Sarsia, 83: 453-496.

Gjøsæter, H. and B. Bogstad. - 1998. Effects of the presence of herring (Clupea harengus) on the stock-recruitment relationship of Barents Sea capelin (Mallotus villosus). Fish. Res., 38: 57-71.

Hamre, J. - 1994. Biodiversity and the exploitation of the main fish stocks in the Norwegian-Barents Sea ecosystem. Biodiv. Cons., 3: 473-492.

Hilborn, R. and C.J. Walters. - 1992. Quantitative fisheries stock assessment. Chapman and Hall, New York.

Holland, J.H. - 1975. Adaptation in natural and artificial systems. The University of Michigan Press, Ann Arbor.

Hurrell, J.W. - 1995. Decadal trends in the North Atlantic Oscillation: regional temperatures and precipitation. Science, 169: 676-679. 
Huse, G. and J. Giske. - 1998. Ecology in Mare Pentium: an individual-based spatio-temporal model for fish with adapted behaviour. Fish. Res., 37: 163-178.

Huse, G. and H. Gjøsæter. - 1999. A neural network approach for predicting stock abundance of the Barents Sea capelin. Sarsia, 84: 457-464.

Huse, G. and R. Toresen. - 2000. Juvenile herring prey on Barents Sea capelin larvae. Sarsia, 85: 385-391.

ICES. - 2001. Report of the Arctic Fisheries Working Group. ICES CM 2001/ ACFM:19, ICES.

Jakobsson, J. - 1992. Recent variability in the fisheries of the North Atlantic. ICES Mar. Sci. Symp., 195: 291-315.

Komatsu, T., I. Aoki, I. Mitani and T. Ishii. - 1994. Prediction of catch of Japanese sardine larvae in Sagami Bay using a neura network. Fish. Sci., 60: 385-391.

Laë, R., S. Lek and J. Moreau. - 1999. Predicting fish yield of African lakes using neural networks. Ecol. Modell., 120: 325-335.

Lek, S. and J.F. Guegan. - 1999. Artificial neural networks as a tool in ecological modelling, an introduction. Ecol. Modell., 120: 65-73.

Marshall, C.T., N.A. Yaragina, Y. Lambert and O.S. Kjesbu. 1999. Total lipid energy as a proxy for total egg production by fish stocks. Nature, 402: 288-290.

Marshall, C.T., N.A. Yaragina, B. Ådlandsvik and A.V. Dolgov. 2000. Reconstructing the stock-recruit relationship for Northeast Arctic cod using a bioenergetic index of reproductive potential. Can. J. Fish. Aquat. Sci., 57: 1-10.

Mehl, S. and K. Sunnanå. - 1991. Changes in growth of Northeast Arctic cod in relation to food consumption in 1984-1988. ICES Mar. Sci. Symp., 193: 109-112.

Michalsen, K., G. Ottersen and O. Nakken. - 1998. Growth of North-east Arctic cod (Gadus morhua L.) in relation to ambient temperature. ICES J. Mar. Sci., 55: 863-877.

Mitchell, M. - 1996. An introduction to genetic algorithms. The MIT Press, Cambridge, MA.

Myers, R. - 1998. When do environment-recruitment correlations work? Rev. Fish Biol. Fish., 8: 285-305.

Nakken, O. - 1994. Trends and fluctuations in the Arcto-Norwegian cod stock. ICES Mar. Sci. Symp., 198: 212-228.

Ottersen, G. and S. Sundby. - 1995. Effects of temperature, wind and spawning stock biomass on recruitment of Arcto-Norwegian cod. Fish. Oceanogr., 4: 278-292.

Planque, B. and T. Frédou. - 1999. Temperature and the recruitment of Atlantic cod (Gadus morhua). Can. J. Fish. Aquat. Sci., 56: 2069-2077.

Ponomarenko, V.P. and I.Y. Ponomarenko. - 1975. Consumption of the Barents Sea capelin by cod and haddock. ICES CM/F:10, ICES.

Pope, J.G. - 1972. An investigation of the accuracy of virtual population analysis using cohort analysis. Res. Bull. Int. Comm. North West Atl. Fish., 9: 65-74.

Rummelhart, D.E., G.E. Hinton and R.J. Williams. - 1986. Learning representations by back-propagating errors. Nature, 323: 533-536.

Saila, S.B. - 1996. Guide to some computerised artificial intelligence methods. In: B. Megrey and E. Moksness (eds.), Computers in fisheries research, pp. 8-40. Chapman \& Hall, London.

Sundby, S. - 2000. Recruitment of Atlantic cod stocks in relation to temperature and action of copepod populations. Sarsia, 85: 277-298.

Sundby, S., H. Bjørke, A.V. Soldal and S. Olsen. - 1989. Mortality rates during the early life stages and year class strength of Northeast Arctic cod (Gadus morhua L.). Rapp. Proc. Verb. Réun. Cons. Int. l'Exp. Mer, 191: 351-358.

Tereshchenko, V.V. - 1996. Seasonal and year-to-year variations of temperature and salinity along the Kola meridian transect. ICES CM/C:11, ICES.

Toresen, R. - 2000. Havets ressurser 2000. Institute of Marine Research, Bergen, Norway.

van Rooij, A.J.F., L.C. Jain and R.P. Johnson. - 1996. Neural Network training using Genetic Algorithms. World Scientific, Singapore.

Yaragina, N.A. and C.T. Marshall. - 2000. Trophic influences on interannual and seasonal variation in the liver condition index of Northeast Arctic cod (Gadus morhua). ICES J. Mar. Sci., 57: 42-55.

\section{APPENDIX}

This appendix illustrates how predictions are calculated using a trained ANN. The case presented is prediction of cod biomass for the year 1999 one year ahead using the best model (Fig. 4). The standardised input values applied are $\mathrm{CB}_{98}=0.525, \mathrm{TA}_{98}=0.795, \mathrm{CF}_{98}=0.538$, where the subscripts refer to the year of input data observation, 1998 in this case. The evolved weights and biases are listed in Table A1. Putting these weights and input values into Eqs. 1-4 yields a predicted biomass value for 1999 of 1.05 million tonnes.

TABLE A1. - The evolved input weights, biases of hidden nodes, and output weights of one of the 10 replicate computer runs trained to predict the biomass of cod in 1999. The weight subscripts refer to the location of weights and biases in the ANN (Fig. 2).

\begin{tabular}{lccccccccc}
\hline & \multicolumn{4}{c}{ Input weights } & & \multicolumn{3}{c}{ Biases } \\
$I W_{11}$ & $I W_{21}$ & $I W_{31}$ & $I W_{12}$ & $I W_{22}$ & $I W_{32}$ & $B_{1}$ & $B_{2}$ & \\
\hline-4.682 & -0.266 & 2.496 & 0.157 & -3.39 & -1.661 & 0.349 & 2.34 & -1.884 \\
\hline
\end{tabular}


